\title{
Obstacle Avoidance for Autonomous Mobile Robots Based on Position Prediction Using Fuzzy Inference
}

\author{
Takafumi Suzuki and Masaki Takahashi \\ Keio University \\ Japan
}

\section{Introduction}

In the future, it's not difficult to image that we will often come across many autonomous mobile robots traversing densely populated place we live in. In such situation, because the autonomous mobile robots need to carry out their tasks in a place with unknown obstacles, the obstacle avoidance is one of the important functions of the robots. With a view to implementation of autonomous mobile robot working in doors, we employ an omnidirectional platform as shown in Fig. 1 (left). For experimental verification, an omnidirectional mobile robot shown in Fig. 1 (right) is developed. The robot has an omnidirectional camera for environmental recognition, and can move to all directions by four omni wheels.

While there are many studies about obstacle avoidance method focusing attention on possibility of avoidance, this paper presents the method focusing on not only possibility but also safer trajectory of avoidance. Even if there are the same situations that the robot needs to avoid a static obstacle, timing of beginning avoidance behaviour should vary according to the robot speed. If the obstacles are moving also, the timing should vary according to the velocities of the obstacles. To cite a case, in a situation that a robot and an obstacle go by each other as shown in Fig. 2, the robot should avoid along the curved line like (iii) according to the speeds of the obstacle and own speed. In order to get to the goal with efficient and safe avoidance behaviour in the unknown environment for the robots, predicting the future obstacles' positions by their current motions is needed.

This paper introduces a real-time obstacle avoidance method introducing the velocity of obstacle relative to the robot. By means of considering predicted positions of the robot and the obstacle calculated from the time and the relative velocity, the robot can begin the avoidance behaviour at an appropriate time according to the velocity of the obstacle and the robot.

Some researches focus attention on the velocity of obstacle (Ko \& Lee, 1996) to avoid moving obstacles efficiently. In this research, virtual distance function is defined based on distance from the obstacle and speed of obstacle, however, only projection of the obstacle velocity on the unit vector from the obstacle to the robot is considered. In other words, the velocity of the robot is not considered. 

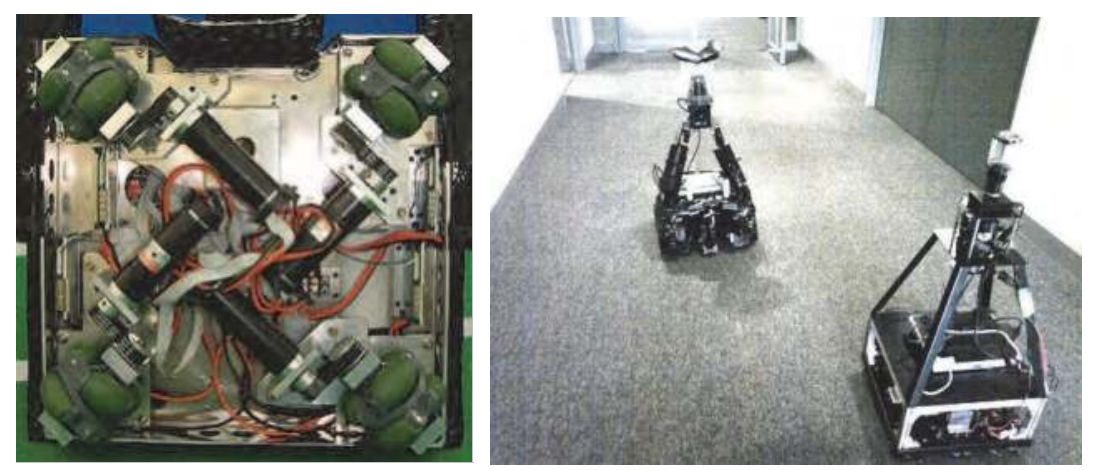

Fig. 1. An omni-directional platform of a prototype robot (left), a situation that the robot needs to avoid the other robot (right)

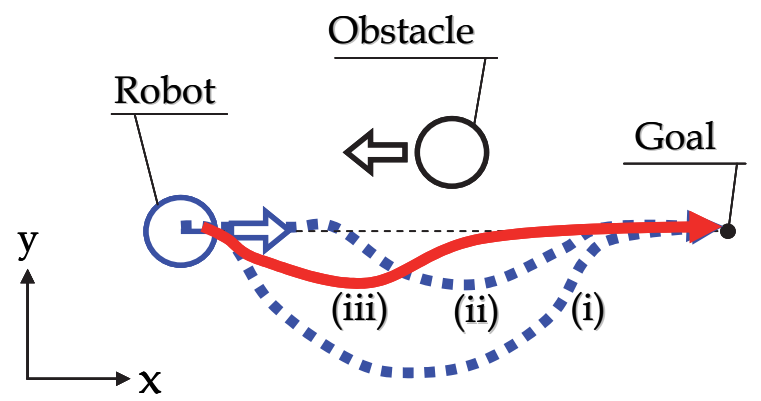

Fig. 2. A situation of obstacle avoidance

On the other hand, in (Ge \& Cui, 2002), the velocity of the obstacle relative to the robot is considered. Our approach also employs the relative velocity. In addition to this approach, a position vector of the obstacle relative to the robot in the future is calculated by the relative position and the velocity.

In order to solve the real-time motion planning problem, there are effective methods (Khatib, 1986) (Arkin, 1989) (Borenstein \& Koren, 1991) (Fox et al., 1997). Fuzzy potential method (FPM) (Tsuzaki \& Yoshida, 2003) (Otsuka et al. 2005) is also one of the effective methods. In this research, the method was applied to an autonomous mobile robot which plays soccer. By adequate designing of potential membership function (PMF), it was realized that wheeled robots got to the goal with conveying a soccer ball and avoiding obstacles. This method is easy to understand at a glance. However, in dynamic environment, to avoid moving obstacles efficiently, more specific guideline of designing is desired. In this paper, we introduce design method of PMF considering the predicted positions and discuss the availability by comparing the design of PMF considering the relative velocity and that not considering.

In this paper, for the purpose of avoiding the moving obstacle safely and smoothly, design methods of the potential membership function (PMF), which is considering the velocity of the obstacle relative to the robot, are presented. 

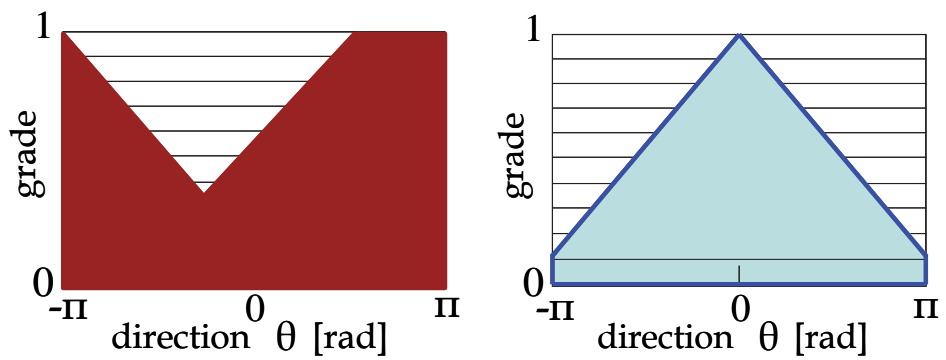

Fig. 3. Potential membership functions (PMFs): for an obstacle (left) and a goal (right).

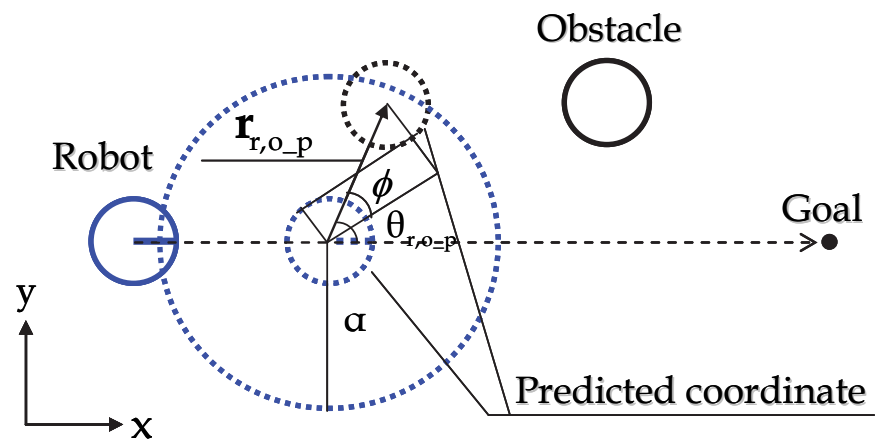

Fig. 4. Predicted coordinates of a robot and an obstacle

\section{Fuzzy potential method (FPM)}

In the fuzzy potential method (FPM), a current command velocity vector considering element actions is decided in real time. Element actions are represented as potential membership functions (PMFs), and then they are integrated by means of fuzzy inference. Furthermore, by using a state evaluator, the PMFs are modified adaptively according to the situation. The directions on the horizontal axis in Fig. 3 correspond to the directions which are from $-\Pi$ to $\Pi$ radians and measured clockwise from the front direction of the robot. The grade for the direction is represented on the vertical axis. By use of the grade, direction and configured maximum and minimum speed, the current command velocity vector $\mathbf{v}_{\text {out }}=\left(\mathrm{v}_{\mathrm{r}}^{\mathrm{x}}, \mathrm{v}_{\mathrm{r}}^{\mathrm{y}}\right)$ is calculated. The command velocity vector is realized by an omni directional platform.

PMF idea allows us to represent our knowledge and experiences easily, and furthermore it gives us easy understanding. The grade can be seen as a desire for each direction of the robot. In this paper, to discuss an obstacle avoidance problem, methods for generating of PMF to head to a goal and to avoid moving obstacles are introduced. This method has two steps. First step is generating PMFs. Second step is deciding the command velocity vector by use of fuzzy inference to integrate the PMFs. Hereinafter, design method of PMF considering the obstacle velocity relative to the robot and way to decide the command velocity vector by fuzzy inference are described 


\section{FPM considering the relative velocity}

To realize the obstacle avoidance in dynamic environment, the proposed method employs two different PMFs, one is considering vectors of obstacle's position and obstacle's velocity relative to the robot and the other is to head to the goal. PMF is denoted by $\mu$ which is function of $\theta$. Note $\theta$ is the direction from $-\Pi$ to $\Pi$ radians measured clockwise from front direction of the robot. To simplify the analysis, it is assumed that the autonomous mobile robot detects obstacles by equipped external sensors and is capable of calculating the positions and velocities of obstacles relative to the robot. The shapes of the robot and the obstacles are treated as circles on 2D surface.

\subsection{Design of PMFs}

\subsubsection{PMF for an obstacle}

To avoid moving obstacles safely and efficiently, an inverted triangular PMF by specifying a vertex, height and base width is generated. Because this PMF considers future positions of the robot and the obstacle, the robot can start avoiding the obstacle early and be prompted not to go on to the future collision position. For the purpose of safe avoidance, the PMF $\mu_{\mathrm{o}}$ is generated.

First, in order to predict the future state of both obstacle and robot with the aim of efficient avoidance, a predicted relative position vector, in $\gamma \mathrm{T}$ seconds, $\mathbf{r}_{\mathrm{r}, \mathrm{o}_{-} \mathrm{p}}=\left(\mathrm{r}_{\mathrm{x}_{\mathrm{P}}}, \mathrm{r}_{\mathrm{y} \_\mathrm{p}}\right)$ is calculated as following equation:

$$
\mathbf{r}_{\mathrm{r}, \mathrm{o} \_\mathrm{p}}=\mathbf{r}_{\mathrm{r}, \mathrm{o}}+\gamma T \mathbf{v}_{\mathrm{r}, \mathrm{o}}
$$

where $r_{r, o}=\left(r_{x}, r_{y}\right)$ is current position vector of the obstacle relative to the robot, and $\mathbf{v}_{\mathrm{r}, \mathrm{o}}=\left(\mathrm{v}_{\mathrm{x}}, \mathrm{v}_{\mathrm{y}}\right)$ is the current velocity vector of obstacle relative to the robot. $\gamma$ is an arbitrary parameter from 0 to 1 . $\mathrm{T}$, which is the time until the distance between the obstacle and the robot is minimum, is defined as following equation:

$$
\mathrm{T}=\frac{\left\|\mathbf{r}_{\mathrm{r}, \mathrm{o}}-\mathbf{p}\right\|}{\left\|\mathbf{v}_{\mathrm{r}, \mathrm{o}}\right\|}
$$

where $\mathbf{p}=\left(\mathrm{p}_{\mathrm{x}}, \mathrm{p}_{\mathrm{y}}\right)$ is a position vector of the obstacle relative to the robot when a distance in the future between the obstacles and the robot is minimum. $\mathbf{p}$ is calculated by means of relative position and velocity vector as following equation:

$$
\left(\begin{array}{c}
\mathrm{p}_{\mathrm{x}} \\
\mathrm{p}_{\mathrm{y}}
\end{array}\right)=\left(\begin{array}{c}
\left\{\left(\mathrm{v}_{\mathrm{y}} / \mathrm{v}_{\mathrm{x}}\right) \mathrm{r}_{\mathrm{y}}-\mathrm{r}_{\mathrm{x}}\right\} /\left(\mathrm{v}_{\mathrm{y}} / \mathrm{v}_{\mathrm{x}}+\mathrm{v}_{\mathrm{x}} / \mathrm{v}_{\mathrm{y}}\right) \\
-\left(\mathrm{v}_{\mathrm{y}} / \mathrm{v}_{\mathrm{x}}\right) \mathrm{p}_{\mathrm{x}}
\end{array}\right)
$$

As described above, the predicted relative position vector, at the time $\gamma \mathrm{T}$ seconds from now, $\mathbf{r}_{\mathrm{r}, \mathrm{o}-\mathrm{p}}$ is calculated as Fig. 4 shows. By use of this position vector, a predicted obstacle direction relative to the robot $\theta_{r, o \_p}$ is calculated as following:

$$
\theta_{\mathrm{r}, \mathrm{o} \_\mathrm{p}}=\arctan \left(\frac{\mathrm{r}_{\mathrm{y} \_\mathrm{p}}}{\mathrm{r}_{\mathrm{x} \_\mathrm{p}}}\right)
$$


where $\theta_{\mathrm{r}, \mathrm{o} \_\mathrm{p}}$ is decided to be the vertex of the inverted triangle.

Next, as a measure to decide how far the robot should depart from the obstacle, a is defined as the height of the inverted triangular PMF. a is described as following equation:

$$
\begin{gathered}
a=\frac{a-\left\|r_{r, o \_p}\right\|}{a-R_{r, o}} \quad \text { if }\left\|r_{r, o \_p}\right\|<\alpha \\
R_{r, o}=R_{r}+R_{o}
\end{gathered}
$$

where $R_{r}$ and $R_{o}$ denote respectively the radius of the robot and that of the obstacle treated as circles. If the calculated obstacle position at $\gamma^{T}$ seconds later is inside of a circle with radius a from the robot position at $\gamma \mathrm{T}$ seconds later, the PMF for obstacle avoidance considering the relative velocity is generated. In other words, if a predicted relative distance $\left\|\mathbf{r}_{\mathrm{r}, \mathrm{o}_{\mathrm{O}} \mathrm{p}}\right\|$ is below $\mathrm{a}, \mathrm{a}$ is defined and the inverted triangular PMF corresponding to the obstacle is generated. Smaller the predicted relative distance is, larger the value of a is. In addition, a base width of inverted triangular PMF is decided by following equation:

$$
\mathrm{b}=\eta\left\|\mathbf{v}_{\mathrm{r}, \mathrm{o}}\right\|+\phi
$$

where $\phi$ is decided based on the sum of radiuses of the robot and the obstacle $\left(R_{\mathrm{r}, \mathrm{o}}\right)$, and predicted relative position vector $\left(\mathbf{r}_{\mathrm{r}, \mathrm{o}-\mathrm{p}}\right)$ as Fig. 4 shows. $\phi$ is calculated by following equation:

$$
\phi=\arcsin \left(\frac{\mathrm{R}_{\mathrm{r}, \mathrm{o}}}{\left\|\mathrm{r}_{\mathrm{r}, \mathrm{o} \_\mathrm{p}}\right\|}\right) .
$$

b increases up to $\Pi$ radian in proportion to an absolute value of the relative velocity and predicted relative distance. If the obstacle comes at rapidly, for instance, the value of $b$ increases. Hence, the base width grows shown in Fig. 5, and the value of grade for the direction of the obstacle relative to the robot comes about to be reduced. $\eta$ is a gain.

As mentioned above, by deciding the vertex, the height and the base width of inverted triangle considering the predicted relative position, PMF $\mu_{\mathrm{o}}$, which aims to early starting of avoidance behavior and prompt the direction of the velocity vector to be far from obstacle direction in response to the fast-moving obstacle, is generated.

\subsubsection{PMF for a goal}

To head to the goal, a PMF $\mu_{d}$ shaped like triangle is generated as shown in Fig. 6. As a measure to decide how much the robot want to head to the goal, $c$ is defined as the height of the triangular PMF. $c$ gets the maximum value at an angle of the goal direction $\theta_{d}$, which is relative to the front direction of the robot, and is described as following equation:

$$
c= \begin{cases}\frac{\left\|\mathbf{r}_{r, d}\right\|}{\varepsilon} & \text { if }\left\|\mathbf{r}_{r, d}\right\| \leq \varepsilon \\ 1.0 & \text { if }\left\|\mathbf{r}_{r, d}\right\|>\varepsilon\end{cases}
$$




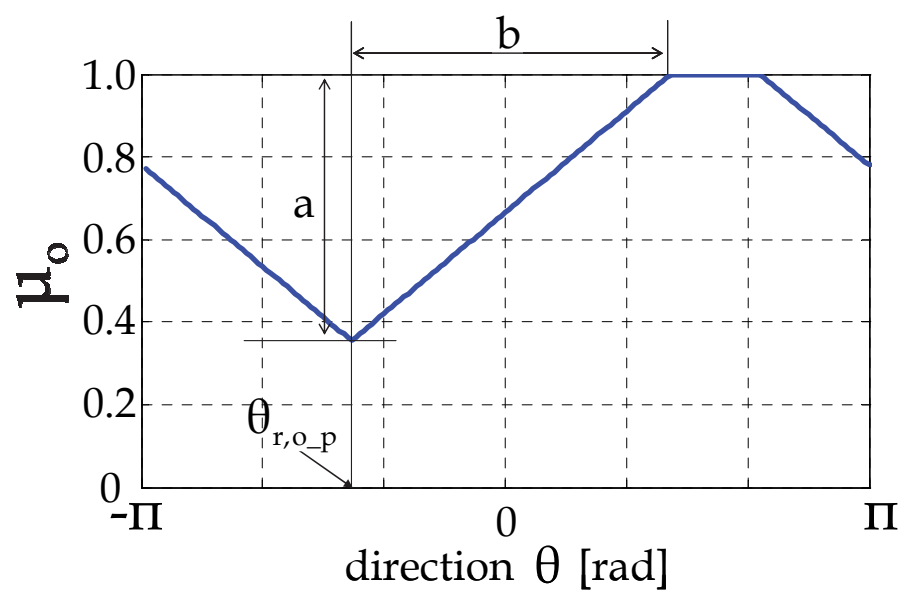

Fig. 5. A PMF for an obstacle considering relative velocity

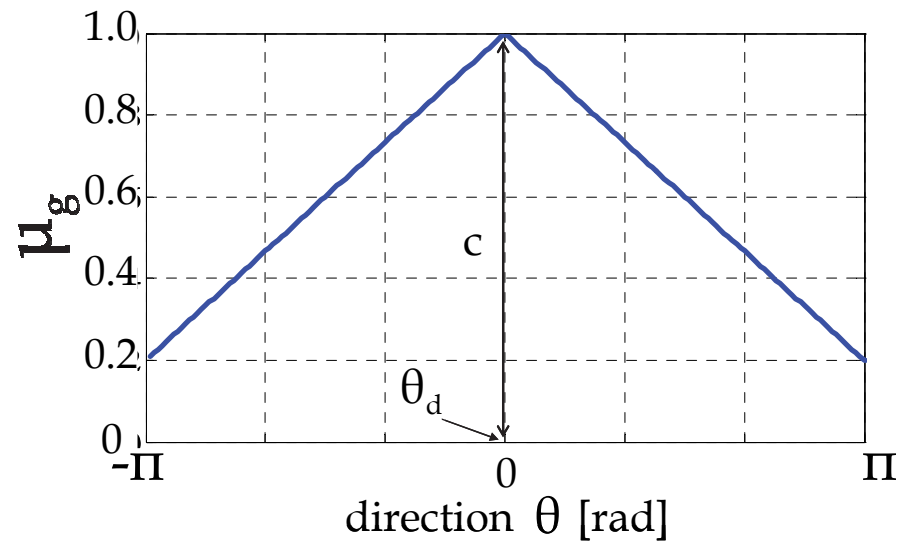

Fig. 6. A PMF for a goal

where $\left\|r_{r, d}\right\|$ is an absolute value of the position vector of the goal relative to the robot. $\varepsilon$ is constant. If $\left\|\mathbf{r}_{\mathrm{r}, \mathrm{d}}\right\|$ is below $\varepsilon, c$ is defined. The shorter the distance between the obstacle and the robot is, the smaller $c$ becomes. Therefore the robot can decelerate and stop stably.

\subsection{Calculation of command velocity vector by fuzzy inference}

The proposed method employs fuzzy inference to calculate the current command velocity vector. Specifically, The PMF $\mu_{o}$, which considers the velocity of obstacle relative to the robot, and the PMF $\mu_{d}$, which is to head to the goal, are integrated by fuzzy operation into a mixed PMF $\mu_{\text {mix }}$ as shown in Fig. 7. $\mu_{\text {mix }}$ is an algebraic product of $\mu_{o}$ and $\mu_{d}$ as following equation:

$$
\mu_{\text {mix }}=\mu_{d} \cdot \mu_{o}
$$




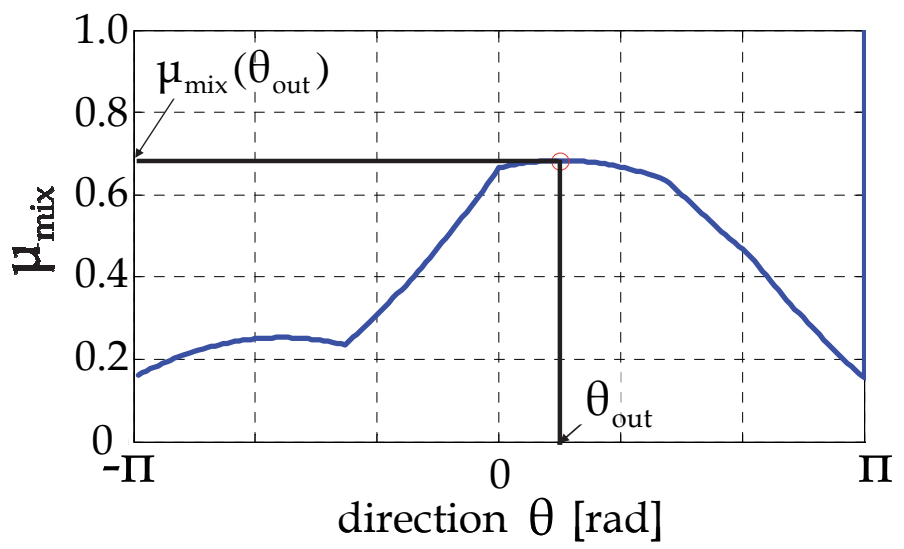

Fig. 7. A mixed PMF

Finally, by defuzzifier, the command velocity vector $\mathbf{v}_{\text {out }}=\left(\mathrm{v}_{\mathrm{r}}^{\mathrm{x}}, \mathrm{v}_{\mathrm{r}}^{\mathrm{y}}\right)$ is calculated as a traveling direction $\theta_{\text {out }}$ and an absolute value of the reference speed of the robot $v_{\text {out }}$ base on the mixed PMF $\mu_{\text {mix }}$. $\theta_{\text {out }}$ is decided as the direction $\theta_{i}$ which makes a following function $f(\theta)$ maximum.

$$
f(\theta)=\sum_{i=j-n}^{j+n} \mu_{\text {mix }}\left(\theta_{i}\right)
$$

where $\mathrm{n}$ is the parameter to avoid choosing undesirable $\theta_{\mathrm{i}}$ caused by such as noises on the sensor data. Based on $\theta_{\text {out }}, \mathrm{v}_{\text {out }}$ is calculated as following equation:

$$
\mathrm{v}_{\text {out }}=\mu_{\text {mix }}\left(\theta_{\text {out }}\right)\left(\mathrm{v}_{\text {max }}-\mathrm{v}_{\text {min }}\right)+\mathrm{v}_{\text {min }}
$$

where $\mu_{\text {mix }}\left(\theta_{\text {out }}\right)$ is the mixed PMF $\mu_{\text {mix }}$ corresponding to the $\theta_{\text {out }}, \mathrm{v}_{\text {max }}$ and $\mathrm{v}_{\text {min }}$ are configured in advance respectively as higher and lower limit of the robot speed.

Based on $\theta \square_{\text {out }}$ and $\mathrm{v}_{\text {out }}, \mathbf{v}_{\text {out }}=\left(\mathrm{v}_{\mathrm{r}}^{\mathrm{x}}, \mathrm{v}_{\mathrm{r}}^{\mathrm{y}}\right)$ is calculated as following equation:

$$
\begin{aligned}
& \mathrm{v}_{\mathrm{r}}^{\mathrm{x}}=\mathrm{v}_{\text {out }} \cos \theta_{\text {out }} . \\
& \mathrm{v}_{\mathrm{r}}^{\mathrm{y}}=\mathrm{v}_{\text {out }} \sin \theta_{\text {out }} .
\end{aligned}
$$

\subsection{Visualization for PMF on two-dimension surface}

It would be convenient to have a visualizer that show us why the robot will go on to the direction. In the proposed method, we can see aspects of the PMFs on two dimension surface and understand easily the reason for choice of the direction. For example, a PMF described on polar coordinate shown in Fig. 9 (left) is comparable to the PMF described on $\mathrm{x}-\mathrm{y}$ coordinate shown in Fig. 9 (right). 

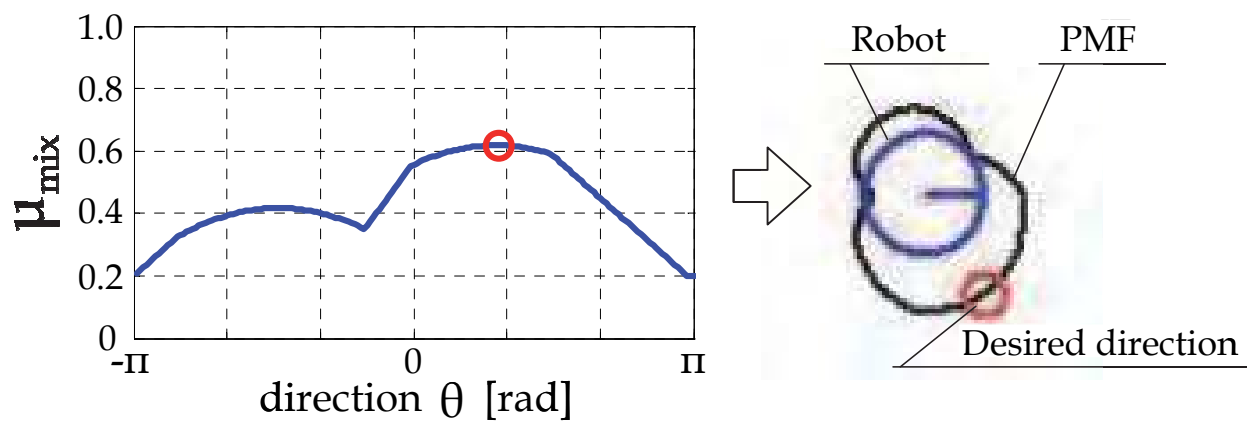

Fig. 9. Visualization of PMF

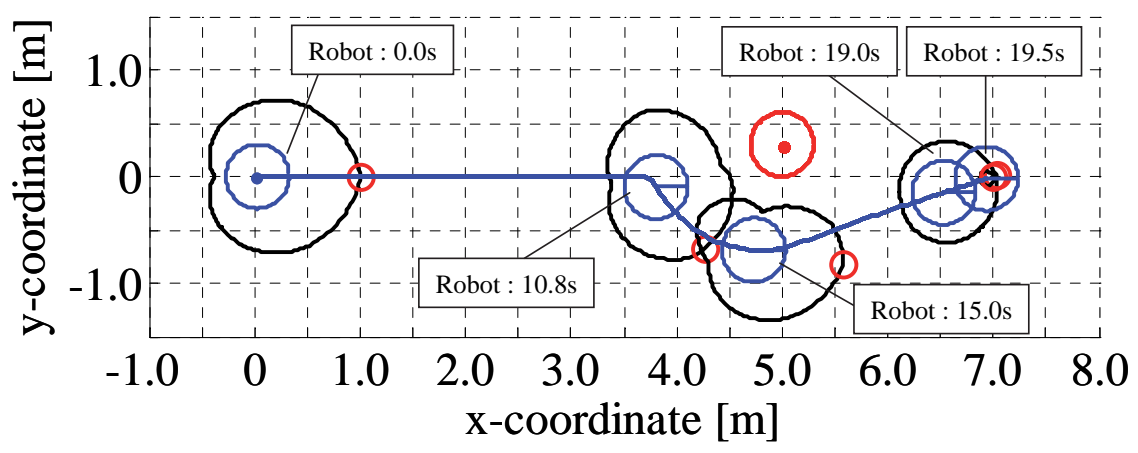

(a) not using PMF considering relative velocity

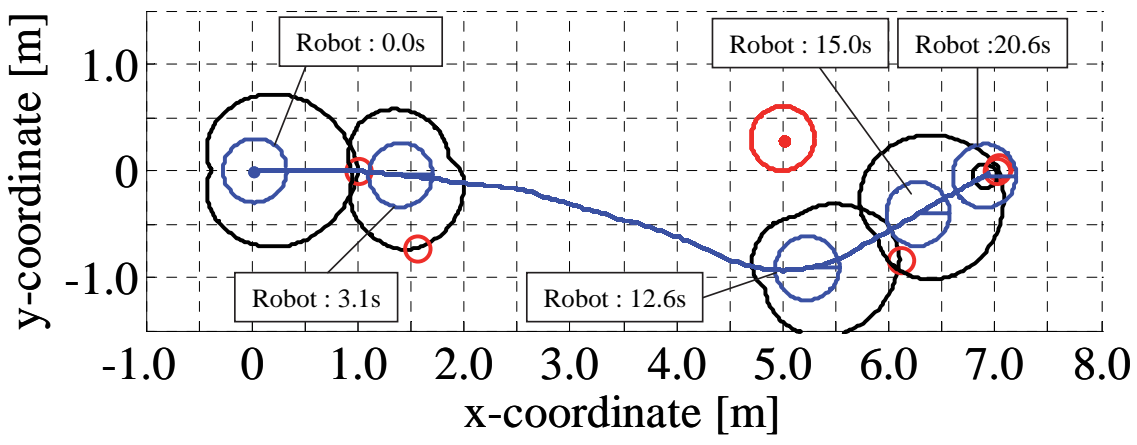

(b) using PMF considering relative velocity

Fig. 10. Simulation results of an obstacle avoidance going by each other when speed of obstacle was $0.0 \mathrm{~m} / \mathrm{s}$ and of a robot was $0.5 \mathrm{~m} / \mathrm{s}$ 


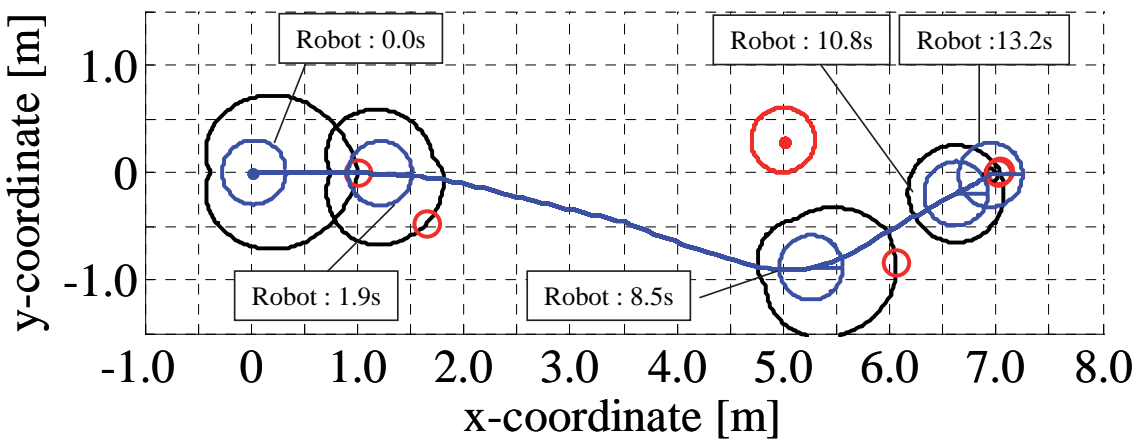

Fig. 11. Simulation results of an obstacle avoidance going by each other when speed of obstacle was $0.0 \mathrm{~m} / \mathrm{s}$ and of a robot was $0.8 \mathrm{~m} / \mathrm{s}$

\section{Simulation results}

To verify the effectiveness of the proposed method that employs PMF considering the velocity of the obstacle of the robot, numerical simulations which assumed an obstacle avoidance of autonomous omni-directional mobile robot were carried out.

In this simulations as shown in Figs. 10-12, the radius of robot and obstacle were supposed to be both $0.3 \mathrm{~m}$, therefore, $R_{r, o}=0.6 \mathrm{~m}$. $\alpha$ in Eq. (5) was $1.6 \mathrm{~m} . \gamma$ in Eq. (1) was 0.7. $\varepsilon$ in Eq. (9) is $1.0 \mathrm{~m}$.

Figure 10, 11 and 12 show the simulation results when the robot passed the obstacle. Initial positions of the robot and the obstacle were respectively $(0.0 \mathrm{~m}, 0.0 \mathrm{~m})$ and $(5.0 \mathrm{~m}, 0.3 \mathrm{~m})$. The goal position of the robot was $(7.0 \mathrm{~m}, 0.0 \mathrm{~m})$. In the situation in Figure 10, the higher limit of robot speed was $\mathrm{v}_{\max }=0.5 \mathrm{~m} / \mathrm{s}$, the lower one was $\mathrm{v}_{\text {min }}=0.0 \mathrm{~m} / \mathrm{s}$. The higher limit of acceleration of the robot was $a_{r}=1.0 \mathrm{~m} / \mathrm{s}^{2}$. The simulations have done with two different obstacle speed $\mathrm{v}_{\mathrm{o}}=0.0,0.5 \mathrm{~m} / \mathrm{s}$, which the direction was negative on $x$-axis. Figure 10(a) and (b) show respectively the trajectory of the robot that the PMF for obstacle avoidance is generated without considering the relative velocity and that with considering the relative velocity, when $\mathrm{v}_{\mathrm{o}}=0.0 \mathrm{~m} / \mathrm{s}$.

As shown in Figure 10(a), the robot got close to the obstacle because the relative velocity was not considered. On the other hand, in Figure 10(b), the robot succeeded at the early starting of avoidance behaviour due to generating PMF by use of predicted information based on the relative velocity. In addition to the situation as in Figure 10(b), in Figure 11, the higher limit of the robot speed has been changed: $v_{\max }=0.8 \mathrm{~m} / \mathrm{s}$. Even if the robot speed becomes higher, the robot succeeded in efficient avoidance.

In Figure 12(a) and (b), the trajectories of the robot, with PMF considering the relative velocity and not considering that, when the obstacle speed $\mathrm{v}_{\mathrm{o}}=0.5 \mathrm{~m} / \mathrm{s}$. In (a), due to delay of starting avoidance behaviour, the robot collided with the obstacle. On the other hand, in (b), due to the early starting of the avoidance behaviour, the robot succeeded at the obstacle avoidance. 
From these simulation results, it is confirmed that by an associating the PMF for avoidance with the relative velocity, higher the obstacle speed is, earlier the timing of the avoidance behaviour of the robot is, therefore the ability of avoiding obstacle can be enhanced.

In order to verify the effectiveness of the proposed method, simplified experiments were also carried out.

In this experiments as shown in Fig.13 A ball was supposed to be a moving obstacle and is rolled toward the robot. The robot recognized the environment by the omni-directional camera. A position of a goal and that of an obstacle relative to the robot were calculated by extracting features based on objects' colours. The robot size is $\mathrm{L} 0.4 \times \mathrm{W} 0.4 \times \mathrm{H} 0.8 \mathrm{~m}$ and the ball diameter is $0.2 \mathrm{~m}$. The radius of robot and obstacle were supposed to be $0.3 \mathrm{~m}$ and $0.1 \mathrm{~m}$ respectively, therefore, $R_{r, o}=0.4 \mathrm{~m}$. a was set to $1.4 \mathrm{~m}$ when the robot used the proposed PMF which was considering relative velocity. When the robot didn't use the proposed PMF, a was set to $2.4 \mathrm{~m}$. $\gamma$ was 0.7 . $\varepsilon$ was $1.0 \mathrm{~m}$. $\mathrm{v}_{\max }$ was $0.5 \mathrm{~m} / \mathrm{s}, \mathrm{v}_{\min }$ was $0.0 \mathrm{~m} / \mathrm{s}$. $\mathrm{a}_{\mathrm{r}}$ was $1.0 \mathrm{~m} / \mathrm{s}^{2}$.

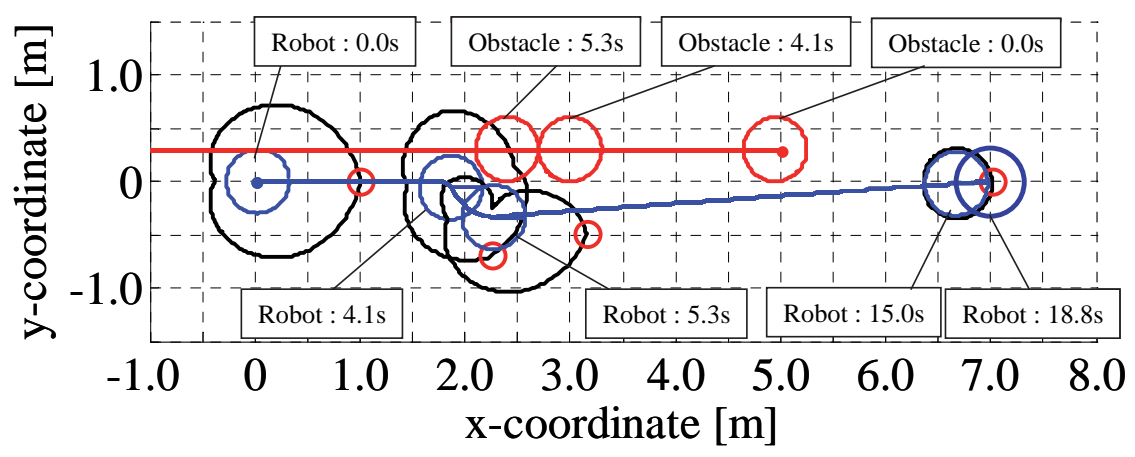

(a) not using PMF considering relative velocity

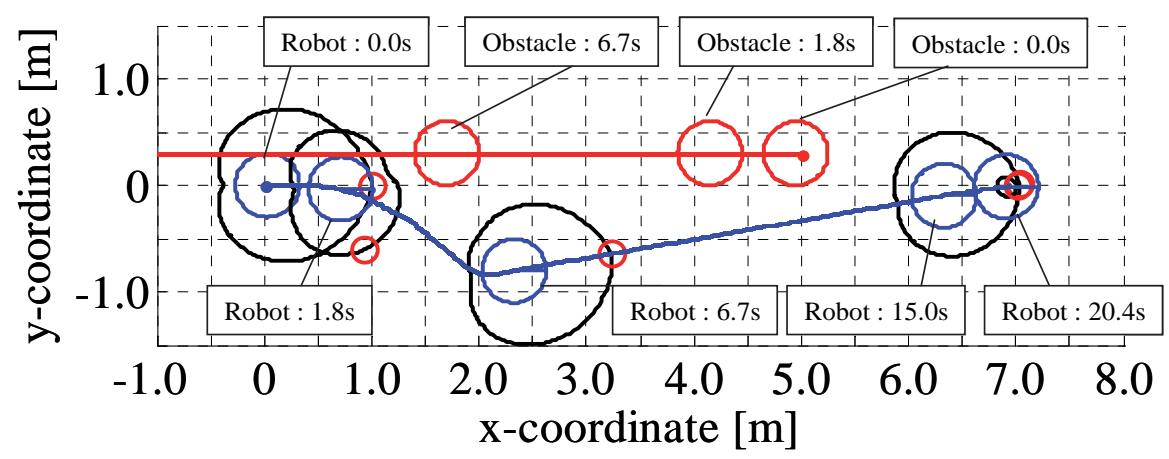

(b) using PMF considering relative velocity

Fig. 12. Simulation results of obstacle avoidance going by each other when speed of an obstacle was $0.5 \mathrm{~m} / \mathrm{s}$ and of a robot was $0.5 \mathrm{~m} / \mathrm{s}$. 
When the robot used the proposed PMF, which was considering relative velocity, as shown in Fig. 13 (a), it succeeded in avoiding the moving ball with smooth trajectory. On the other hand, the robot with the PMF, which was not considering relative velocity, diverged once as shown in Fig. 13 (b).

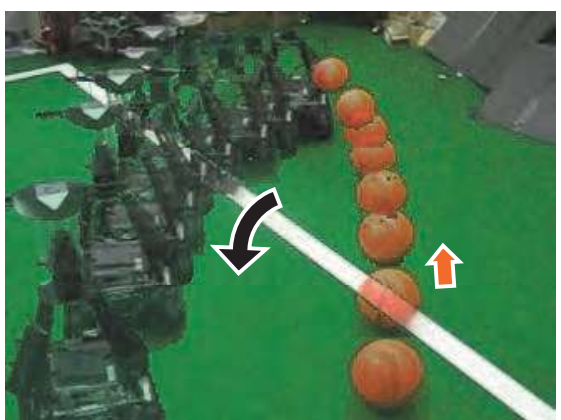

(a)

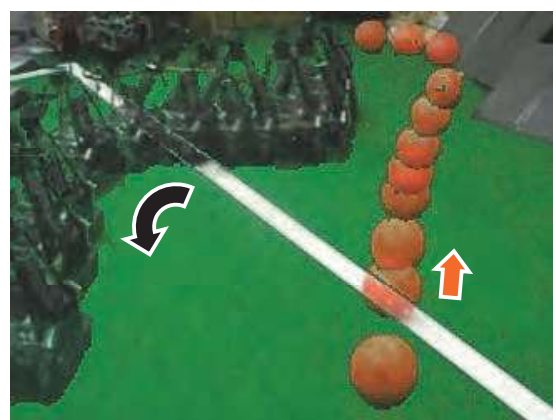

(b)

Fig. 13. Trajectories of the obstacle (ball) and the robot with the PMF considering relative velocity (a) and not considering relative velocity (b)

\section{Conclusion}

In this paper, for the purpose of avoiding the moving obstacle safely and smoothly, design methods of the potential membership function (PMF), taking into consideration the velocity of the obstacle relative to the robot have been presented. The proposed PMF for an obstacle and PMF for a goal are unified by fuzzy inference. By defuzzification, the command velocity vector of the robot is calculated and the obstacle. Numerical simulations and simplified experiments, which assumed an obstacle avoidance of an autonomous omni-directional mobile robot, were done. As the result of the comparison between the design method of PMF using relative velocity and not using, it was confirmed that the PMF using relative velocity enhanced the ability of avoiding the moving obstacle.

\section{References}

Khatib,O., 1986. Real-time Obstacle Avoidance for Manipulators and Mobile Robots, In Int. J. of Robotics Research, vol.5, no.1, pp.90-98.

Arkin, R., C., 1989. Motor schema-based mobile robot navigation, In Int. J. Robotics Research, vol. 8 , no. 4 , pp. $92-96$.

Ko, Y., N., and Lee, H., B., 1996. Avoidability Measure in Moving Obstacle Avoidance Problem and Its Use for Robot Motion Planning, In Proc. of IEEE/RSJ Int. Conf. on Intelligent Robots and Systems (IROS 96), pp.1296-1303.

Ge, S., S., and Cui, J., Y., 2002. Dynamic Motion Planning for Mobile Robots Using Potential Field Method, In Autonomous Robots, vol.13, pp.207-222.

Borenstein, J., and Koren, Y., 1991. The Vector Field Histogram Fast Obstacle Avoidance For Mobile Robots, In IEEE Trans. on Robotics and Automation, Vol.7, No.3, pp.278288. 
Fox, D., Burgard,W. and Thrun,S., 1997. The Dynamic Window Approach to Collision Avoidance, In IEEE Robotics and Automation, Vol. 4, No. 1, pp.1-23.

Tsuzaki, R., Yoshida, K., 2003. Motion Control Based on Fuzzy Potential Method for Autonomous Mobile Robot with Omnidirectional Vision. In Journal of the Robotics Society of Japan . vol.21, no.6, pp.656-662.

Otsuka, F., Fujii, H., Yoshida, K.,,2005. Action Control Based on Extended FPM for an Autonomous Mobile Robot. The 26 $6^{\text {th }}$ Annual Conference of the Robotics Society of Japan. 


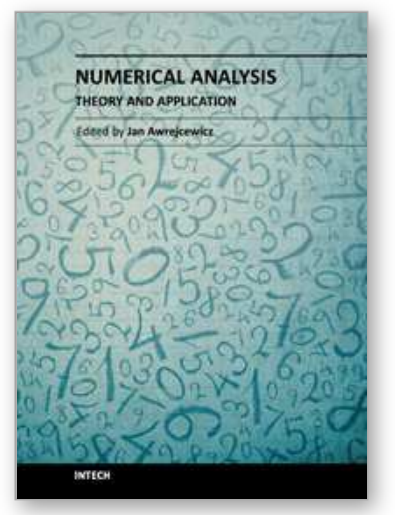

\author{
Numerical Analysis - Theory and Application \\ Edited by Prof. Jan Awrejcewicz
}

ISBN 978-953-307-389-7

Hard cover, 626 pages

Publisher InTech

Published online 09, September, 2011

Published in print edition September, 2011

Numerical Analysis â€“ Theory and Application is an edited book divided into two parts: Part I devoted to Theory, and Part II dealing with Application. The presented book is focused on introducing theoretical approaches of numerical analysis as well as applications of various numerical methods to either study or solving numerous theoretical and engineering problems. Since a large number of pure theoretical research is proposed as well as a large amount of applications oriented numerical simulation results are given, the book can be useful for both theoretical and applied research aimed on numerical simulations. In addition, in many cases the presented approaches can be applied directly either by theoreticians or engineers.

\title{
How to reference
}

In order to correctly reference this scholarly work, feel free to copy and paste the following:

Takafumi Suzuki and Masaki Takahashi (2011). Obstacle Avoidance for Autonomous Mobile Robots Based on Position Prediction Using Fuzzy Inference, Numerical Analysis - Theory and Application, Prof. Jan Awrejcewicz (Ed.), ISBN: 978-953-307-389-7, InTech, Available from: http://www.intechopen.com/books/numericalanalysis-theory-and-application/obstacle-avoidance-for-autonomous-mobile-robots-based-on-positionprediction-using-fuzzy-inference

\section{INTECH}

open science | open minds

\section{InTech Europe}

University Campus STeP Ri

Slavka Krautzeka 83/A

51000 Rijeka, Croatia

Phone: +385 (51) 770447

Fax: +385 (51) 686166

www.intechopen.com

\section{InTech China}

Unit 405, Office Block, Hotel Equatorial Shanghai

No.65, Yan An Road (West), Shanghai, 200040, China 中国上海市延安西路65号上海国际贵都大饭店办公楼 405 单元

Phone: +86-21-62489820

Fax: $+86-21-62489821$ 
(C) 2011 The Author(s). Licensee IntechOpen. This chapter is distributed under the terms of the Creative Commons Attribution-NonCommercialShareAlike-3.0 License, which permits use, distribution and reproduction for non-commercial purposes, provided the original is properly cited and derivative works building on this content are distributed under the same license. 